\title{
BMJ Open The Horsens-Aarhus Femoro Acetabular Impingement (HAFAI) cohort: outcome of arthroscopic treatment for femoroacetabular impingement. Protocol for a prospective cohort study
}

Signe Kierkegaard, ${ }^{1}$ Bent Lund, ${ }^{1}$ Ulrik Dalgas, ${ }^{2}$ Henrik Sørensen, ${ }^{2}$ Kjeld Søballe, ${ }^{3}$ Inger Mechlenburg ${ }^{3}$

To cite: Kierkegaard S, Lund B, Dalgas U, et al. The Horsens-Aarhus Femoro Acetabular Impingement (HAFAI) cohort: outcome of arthroscopic treatment for femoroacetabular impingement. Protocol for a prospective cohort study. BMJ Open 2015;5:e008952. doi:10.1136/bmjopen-2015008952

- Prepublication history for this paper is available online. To view these files please visit the journal online (http://dx.doi.org/10.1136/ bmjopen-2015-008952).

Received 1 June 2015 Revised 27 July 2015 Accepted 17 August 2015

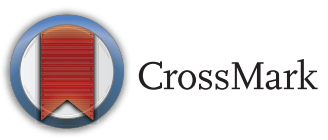

${ }^{1}$ Department of Orthopaedic Surgery, Horsens Hospital, Horsens, Denmark

${ }^{2}$ Section of Sports, Department of Public Health Aarhus University, Aarhus, Denmark

${ }^{3}$ Department of Orthopaedic Surgery, Aarhus University Hospital, Aarhus, Denmark

Correspondence to Signe Kierkegaard; signekierkegaard@hotmail. com

\section{ABSTRACT}

Introduction: During the past decade, it has become increasingly more common to offer hip arthroscopic surgery when treating people with femoroacetabular impingement (FAI). Nevertheless, the latest reviews conclude that it still remains to be properly investigated how surgery affects the patients. Specifically, detailed information on the functional, muscular and mechanical impact of surgery in larger groups is lacking. Furthermore, the long-term outcome of the surgery is still to be investigated.

Methods and analysis: In this prospective cohort study, a total of 60 patients with FAl scheduled for arthroscopic surgery will be followed and tested preoperatively, and again after 3, 6, 9 and 12 months. Assessment includes isokinetic dynamometry evaluating hip flexion and extension; evaluation of functional capacity in a three-dimensional motion laboratory; pain assessment; self-reported function, quality of life, expectation and satisfaction with the surgery; recording of previous and present sporting activities and accelerometry. In addition, data on surgical procedure, rehabilitation progress, adverse events and failure will be recorded. Patients will be compared with an age-matched and gender-matched reference group of 30 persons with no hip, knee, ankle or back problems. Long-term follow-up of this cohort may evaluate possible reoperations and development of hip osteoarthritis. Furthermore, analysis on how subgroups respond to the treatment could be performed together with identification of possible "non-responders".

Ethics and dissemination: The study is approved by the Central Denmark Region Committee on Biomedical Research Ethics (Journal No 1-10-72-239-14). The results from this study will be presented at national and international congresses and published in peerreviewed journals.

Trial registration number: NCT02306525.

\section{Strengths and limitations of this study}

- This prospective cohort study collects objectively measured and self-reported data from patients undergoing arthroscopic hip surgery for femoroacetabular impingement.

- All patients are operated by the same experienced surgeon.

- Patient data are compared with an age-matched and gender-matched healthy reference group.

- For ethical reasons, it is not possible to evaluate the reference group radiologically.

\section{BACKGROUND}

Femoroacetabular impingement (FAI) is caused by an abnormality in the acetabular shape or orientation (pincer-type), by a shape abnormality in the proximal femur (cam-type) or by a mix of the two conditions. ${ }^{12}$ FAI causes repeated minor damage to the labrum and edge of the acetabulum, labral tears and damage to the cartilage lining of the hip joint resulting in pain from the hip and groin region. ${ }^{3}$ The prevalence of cam and/or pincer deformities has previously been investigated in asymptomatic individuals with a mean age of 25 years, where a higher prevalence of cam deformity was seen in athletes $(37 \%)$ compared with the general population $(23 \%) .{ }^{4}$ Asymptomatic pincer deformities were seen in $67 \%$ of the population, although they were less well defined in the literature. ${ }^{4}$ It is unknown why only some deformities become symptomatic, although the symptomatic deformities seem to be linked to a combination of lifestyle factors and genetics. ${ }^{5}$ 
FAI has been suggested to lead to early hip osteoarthritis (OA). ${ }^{6}$ Severe cam-type FAI and reduced internal rotation especially strongly predispose to fast progression of OA, ${ }^{12}$ and an investigation of symptoms and functions related to the specific subtypes of FAI and their predisposition to development of OA is warranted.

Surgical treatment of FAI has been analysed in a variety of studies of the open, combined and arthroscopic methods, respectively, ${ }^{7-11}$ demonstrating that surgery can reduce symptoms caused by impingement in a short-term to mid-term perspective and may prevent future damage to the hip joint. However, different surgical techniques are used and only a few long-term studies on relevant outcomes after surgery exist. ${ }^{8} 9$ Moreover, the most recent reviews conclude that evidence is still lacking to ensure that this type of surgery is effective for patients with $\mathrm{FAI},{ }^{12}$ and that knowledge on how surgery impacts functional performance for the patients in the short-term and long-term perspective is lacking. ${ }^{13}$ Hence, with the rise in arthroscopic treatment of FAI seen in the past decade, ${ }^{14}$ it is important to investigate the outcome of surgery further.

The pathology of FAI alters the intra-articular conditions of the hip joint, making people report pain during motion. ${ }^{15}$ Accordingly, studies have shown that the hip sagittal plane, frontal plane and transverse plane movements are altered during walking, stair climbing and squatting for the patients. ${ }^{16}{ }^{17}$ Hence, it is interesting to investigate the total movement pattern of the lower extremity compared with a reference group with the aim of giving clinicians a measure of the total gait quality. This may be described with the Gait Deviation Index, ${ }^{18}$ quantifying how much patients demonstrate altered kinematics compared with reference persons. Different surgical techniques may restore hip sagittal plane movement during walking to reference values, though not during stair climbing. ${ }^{16}$ Although kinematics are altered for the patients, study results are conflicting regarding kinetics. ${ }^{19-21}$ Nevertheless, a larger study, ${ }^{21}$ which, in contrast to the other studies, was powered for the statistical analysis, found altered hip flexion moment and hip external rotation moment during walking. Further investigation on this matter is necessary in larger groups evaluating hip biomechanics, subgrouping patients into FAI subtypes based on radiography, before clear conclusions on the biomechanical phenomena may be conducted. ${ }^{22}$

Of note, hip muscle function is also altered in patients with FAI. Specifically, Casartelli et $a l^{15}$ described that patients demonstrate decreased isometric muscle strength of the hip flexors, adductors, abductors and external rotators compared with reference persons. Moreover, isometric hip flexion muscle strength was still decreased in eight patients 2.5 years after arthroscopic surgery when compared with healthy controls. ${ }^{23}$ This strongly suggests further evaluation of muscle strength in a larger group of patients involving isometric, concentric and eccentric muscle strength to identify possible target areas for rehabilitation programmes.
In contrast to patients with OA, patients with FAI perform the same level of steps per day as seen in healthy controls. ${ }^{24}$ This is surprising given that many patients report hip pain during daily activities and when doing sports. ${ }^{15}$ No studies were found to evaluate objectively measured physical activity levels besides stride-level activity, and no studies evaluated physical activity after surgery. Our clinical experience is that there is large variation in patient symptoms, ranging from some patients who can hardly engage in daily activities to others who only experience problems during high-impact physical performance. Consequently, it is difficult to plan physical performance tests fitting all patients into one category. ${ }^{25} 26$ This suggests that patients should be stratified according to symptom severity, FAI subtype, gender and age groups when analysed in future studies.

\section{AIM}

The aim of this prospective cohort study is to evaluate biomechanics, muscle strength, physical activity and patient-reported outcomes in patients with FAI before and after arthroscopic surgery compared with a reference group without hip problems.

1. Biomechanics: The aim is to investigate movement patterns for patients with FAI before and 1 year after surgery compared with a reference group. It is hypothesised that:

A. Patient gait and stair ascending and descending kinematics described by the Gait Deviation Index are lower than reference values preoperatively and will increase 1 year postoperatively.

B. Hip flexion moment and hip extension angle are lower during the stance phase of gait and stair descending for the patients. Hip flexion moment and hip extension angle will increase 1 year after surgery compared with the preoperative period.

C. Furthermore, the movement patterns of stepping, sit-stand-sit and jumping will be explored.

D. Subanalyses will be performed after stratification of patients according to the type of FAI.

2. Muscle function: The aim is to investigate hip flexion and extension muscle strength before and 1 year after surgery and its relation to pain during testing. It is hypothesised that:

A. Compared with reference values, isometric, concentric and eccentric hip flexor muscle strength is decreased preoperatively. At 1 year follow-up, muscle strength is expected to increase compared with the preoperative level, without reaching the reference value.

B. Pain levels during muscle strength tests are inversely associated with muscle strength level.

C. It will further be explored how differences between subgroups based on FAI type exist; also, the rate of force development (RFD) will be investigated. 
3. Physical activity: The aim is to investigate physical activity for patients before and 1 year after surgery and to compare this to reference values. Objectively measured daily activities and self-reported (present and previous) sports activities will be investigated.

A. It is hypothesised that the duration of physical activity (walking and cycling) will increase 1 year after surgery.

B. Furthermore, subgroups of the patients are expected to be less active than the reference group preoperatively.

4. Patient-reported outcomes: The aim is to investigate pain-related, function-related and hip-related quality of life measured with the Copenhagen Hip and Groin Outcome Score (HAGOS), ${ }^{27}$ along with expectations for surgery and satisfaction with surgery.

A. It is hypothesised that all subscales of HAGOS will increase 1 year after surgery.

B. Furthermore, if any patients rate below 50 points at the HAGOS pain subscale at 1 year follow-up, their data will be further explored to clarify why their pain is still weak and moderate-to-severe 1 year after surgery.

C. Also, further exploration of the association between the relevant patient-reported subscales and physical performance tests/muscle strength will be performed.

\section{DESIGN}

In this prospective cohort study, 60 patients eligible for arthroscopic treatment of FAI and 30 age-matched and gender-matched reference persons without any hip problems will be included. The patient group will be assessed preoperatively, and again at 3,6 and 9 months and 1 year after surgery, while the reference group will have a single assessment (figure 1).

\section{MATERIAL}

Patients

Inclusion criteria

Scheduled arthroscopic hip surgery at Horsens Hospital, Denmark by the same surgeon (BL), a diagnosis of cam and/or pincer impingement, for patients with cam, an $\alpha$ angle $\geq 55^{\circ}$ on an anteroposterior (AP) standing radiograph, for patients with pincer, a centre edge angle $\geq 25^{\circ}$ on an AP radiograph, no signs of retroversion in the lower 2/3 of the hip joint on an AP radiograph, no posterior wall sign on an AP radiograph, OA grade 0-1 according to Tönnis ${ }^{28}$ classification joint space width of $\geq 3 \mathrm{~mm}$ and age between 18 and 50 years.

\section{Exclusion criteria}

Previous corrective hip surgery of the included hip, FAI secondary to other hip conditions such as the Legg-Calvé-Perthes disease and epiphysiolysis, alloplastic surgery at the hip, knee or ankle region (both legs), cancer, neurological diseases that affect movement pattern, inability to speak or understand Danish and pregnancy at the time of inclusion.

\section{Reference group}

Thirty gender-matched and age-matched persons will be included as a reference group. The reference group will only include persons who state that they have had no known back, hip, knee or ankle pain/problems during the last year. Further, no persons with limitations in walking or a previous major surgery in the hips, knees or ankles and diseases that may affect functional performance (eg, neurological diseases) will be included.

\section{METHODS}

An overview of measurements is shown is table 1 .

\section{Imaging}

Patients will have two low-dose CT scans of their included hip. The CT scans will be used to plan and evaluate the surgery and to categorise patients in subgroups of FAI: (1) cam, (2) pincer and (3) mixed. On both the affected and non-affected hip, an experienced radiologist will determine the $\alpha$ angle, the centre edge angle, the acetabular index (AI) angle and the anterior and posterior acetabular sector angles. Joint space width in the coronal and sagittal planes will be measured at

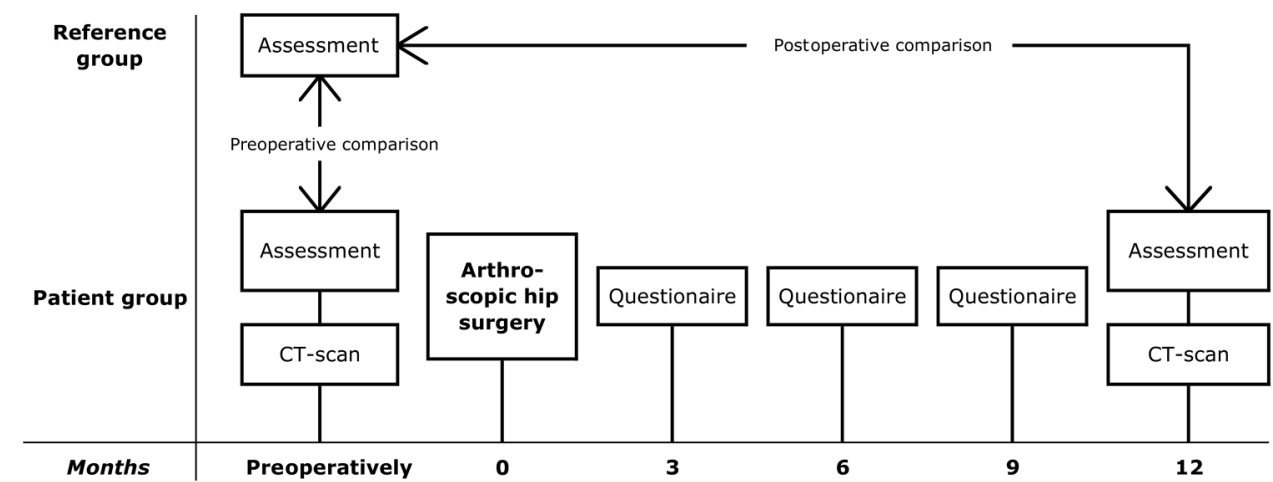

Figure 1 Study design. 
Table 1 Collection of participant characteristics, outcome measures and explanatory variables

\begin{tabular}{|c|c|c|c|c|c|c|c|c|}
\hline \multirow[b]{2}{*}{ Variable } & \multicolumn{7}{|l|}{ Patient group } & \multirow{2}{*}{$\begin{array}{l}\text { Reference } \\
\text { group }\end{array}$} \\
\hline & Preoperatively & $\begin{array}{l}\text { After } \\
\text { surgery }\end{array}$ & $\begin{array}{l}\text { During } \\
\text { rehabilitation } \\
\text { period }\end{array}$ & 3 Month & 6 Month & 9 Month & 1 Year & \\
\hline Height & $x$ & & & & & & $x$ & $x$ \\
\hline Weight & $x$ & & & & & & $x$ & $x$ \\
\hline Fat percentage & $x$ & & & & & & $x$ & $x$ \\
\hline Educational level & $x$ & & & & & & & $x$ \\
\hline Employment & $x$ & & & & & & & $x$ \\
\hline Smoking & $x$ & & & & & & & $x$ \\
\hline Alcohol consumption & $x$ & & & & & & & $x$ \\
\hline Comorbidities & $x$ & & & & & & & $x$ \\
\hline General health & $x$ & & & & & & $x$ & $x$ \\
\hline Previous sports activities & $x$ & & & & & & & $x$ \\
\hline Present sports activities & $x$ & & & $x$ & $x$ & $x$ & $x$ & $x$ \\
\hline Expectations & $x$ & & & & & & & \\
\hline Satisfaction & & & & & $x$ & & $x$ & \\
\hline VAS pain & $x$ & & & $x$ & $x$ & $x$ & $x$ & $x$ \\
\hline HAGOS & $x$ & & & $x$ & $x$ & $x$ & $x$ & $x$ \\
\hline Biomechanical analysis & $x$ & & & & & & $x$ & $x$ \\
\hline $\begin{array}{l}\text { Muscle strength } \\
\text { assessment }\end{array}$ & $x$ & & & & & & $x$ & $x$ \\
\hline $\begin{array}{l}\text { Objectively measured } \\
\text { physical activity }\end{array}$ & $x$ & & & & & & $x$ & $x$ \\
\hline Radiographic evaluation & $x$ & & & & & & $x$ & \\
\hline Surgical parameters & & $x$ & & & & & & \\
\hline $\begin{array}{l}\text { Deviations from } \\
\text { rehabilitation programme }\end{array}$ & & & $x$ & & & & & \\
\hline Adverse events & & & & & & & $x$ & \\
\hline
\end{tabular}

radiographs. For ethical reasons, the reference group will not have their hips CT scanned.

\section{Self-reported outcomes}

Patients will score their hip/groin pain during the past $24 \mathrm{~h}$ during rest and during activity at a $100 \mathrm{~mm}$ Visual Analog Scale (VAS). ${ }^{29}$ Furthermore, they will complete HAGOS for the hip included for surgery. HAGOS is a validated outcome tool used for assessing hip pain and function in young to middle-aged, physically active patients with long-standing hip and/or groin pain. ${ }^{27}$ For the contralateral hip, the subscales 'symptoms', 'stiffness' and 'pain' from HAGOS will be filled. To evaluate general health, a VAS health scale ${ }^{30}$ will be recorded together with reports of comorbidities. Patients will further report any knee or back pain during the past $24 \mathrm{~h}$ on a VAS as well. Patient expectations and reasons for choosing surgery and their expectations for the results of the surgery will be recorded as done by Mannion $e t a l^{31}$ Finally, patients will be asked about their previous and present sports activities, years with pain, pain medication, previous treatment modalities, smoking habits, alcohol intake, education, employment and sick leave.
At follow-up, patients will further report fulfilment of expectations, patient global treatment outcome ${ }^{31}$ and patient-acceptable symptom state. ${ }^{32}$

The reference group will complete HAGOS as well as the questions about previous and present sports activities, smoking habits, alcohol intake, education and employment.

\section{Objective outcome measures}

Motion analysis

Kinematic data will be collected using a threedimensional motion capture system (Qualisys $\mathrm{AB}$, Gothenburg, Sweden) with 8 ProReflex MCU1000 infrared high-speed cameras operating at a sampling frequency of $240 \mathrm{~Hz}$. In addition to the kinematic measurements, during relevant movements, ground reaction force data will be collected at $960 \mathrm{~Hz}$ using a force plate (AMTI OR6-7, Advanced Medical Technology Inc, Watertown, Massachusetts, USA) embedded in the floor. Prior to testing, all participants will be instrumented with 36 retro reflective markers (19 $\mathrm{mm}$ diameter) secured on specific anatomical locations on the pelvis, thighs, shanks and feet as described earlier by Petersen et al..$^{33}$ Furthermore, markers will be placed at the $\mathrm{C} 7$, incisura jugularis and $10 \mathrm{~cm}$ below the 
incisura jugularis to monitor trunk movements. First, a static test will be performed; then static markers will be removed and participants will execute movements including gait, stair climbing, stepping, sit to stand and jumping as described below.

\section{Gait}

The participants will perform five trials at a self-selected walking speed. Their self-selected speed will be measured with two SpeedLight V2 (Swift Performance Equipment, Brisbane, Australia). Afterwards, gait speed will be standardised as $1.39 \mathrm{~m} / \mathrm{s} \pm 10 \%$ to ensure comparability between patients and the reference group before and after surgery. The gait trial will be repeated until at least three valid foot strikes of the right and the left legs at the standardised speed have been recorded. ${ }^{34}$

\section{Stair climbing}

Participants will walk up and down a three-cased staircase (rise $21 \mathrm{~cm}$, run $25 \mathrm{~cm}$ ) with no handrails. The test will be performed with and without an additional weight of approximately $20 \%$ body weight obtained by having the patients carry two dumbbells.

\section{Step}

Participants will step up and down a $40 \mathrm{~cm}$ block step with no use of hand support. Again, the test will be performed with and without an additional weight of approximately $20 \%$ body weight.

\section{Sit-stand-sit}

Participants will rise from an adjustable backless bench and sit down again with their arms crossed in front of the chest.

\section{Jump}

Participants will perform a drop jump from a $40 \mathrm{~cm}$ box. The box will be placed approximately $20 \mathrm{~cm}$ from the force plate. The participants will be instructed to jump down from the box, hitting the force plate with both legs at the same time and then immediately perform a vertical jump with maximal effort.

Pain during movement tasks will be recorded together with a registration of whether the participants are able to perform a movement task, perform with modifications or decline to perform a movement task. The tests are not validated for use in this patient group and will be performed as an explorative study of movement pattern for patients with FAI.

\section{Muscle strength assessment}

Participants will perform a 5 min warm-up on a bicycle ergometer before maximal strength testing. Participants will lay supine on the dynamometer chair (Humac Norm, CSMi, Stoughton, Massachusetts, USA) with the chair back inclined $15^{\circ}$ and the dynamometer rotation axis aligned with the hip rotation centre (greater trochanter). ${ }^{15}$ Hip flexor and extensor strength for both legs will be tested in a randomised order of starting leg and starting muscle group.

Prior to testing, the mass of the tested limb will be measured to adjust for gravity. The muscle group will be tested in the following order: isometric, concentric and eccentric. First, as described by Casartelli et al, ${ }^{15}$ participants will be tested isometrically at $45^{\circ}$. Participants will complete two submaximal familiarisation trials followed by 3-4 Maximum Voluntary Contraction (MVC) trials during which they will be asked to perform maximal effort for 3-4 s. Standardised verbal encouragement will be provided. ${ }^{35}$ After isometric testing, participants will have their isokinetic strength assessed in the range of hip motion from around $10-80^{\circ}$ at an angular velocity of $60^{\circ} / \mathrm{s}$. The participant will be asked to perform a concentric contraction, immediately followed by an eccentric contraction. There will be a resting period of $30 \mathrm{~s}$ between all tests. The procedure for the isokinetic test will be repeated three times. Hereafter, the remaining muscle groups will follow the same procedure.

\section{Clinical examination tests}

The participants will have the FABER (Flexion, ABduction, and External Rotation) test and the anterior impingement test at 90 and $120^{\circ}$ of hip flexion performed, as described by Ratzlaff et al. ${ }^{36}$ A positive test is indicated by pain in the upper/inner thigh or groin.

\section{Objectively measured physical activity}

To objectively measure daily physical activity, participants will be asked to wear a 3-axial accelerometer (AX3 data logger, Axivity, York, UK) during all waking hours for five consecutive days. Participants will record whether they perform any activity not wearing the accelerometer, for how many hours they wore the accelerometer, and at the end of each day they will rate their VAS pain during rest and during activity.

\section{Surgery and rehabilitation}

The arthroscopic hip surgery will be performed by the same experienced surgeon, who will register details of the arthroscopic procedure immediately after departing the operation theatre: anaesthetic data, thrombosis prophylaxis, duration of the surgical procedure and stretch of the leg, extent of cartilage damage on the femoral head and acetabulum, treatment of cartilage damage, number of ancres and complications during surgery.

Postoperatively, patients will follow a standardised rehabilitation programme instructed by experienced physiotherapists. Deviations from the rehabilitation programme will be recorded, and if the patients are admitted to further rehabilitation, the type and duration of this will be recorded as well.

\section{Adverse events and failure}

At 1 year follow-up, adverse events such as nerve injury, infections, deep vein thrombosis, caput femoris necrosis, 
fracture and death will be recorded. The hip arthroscopic surgery will be considered a failure if the patient has received a total hip arthroplasty.

\section{Data analysis}

\section{Motion analysis}

Qualisys Track Manager (Qualisys AB, Gothenburg, Sweden) software will be used to collect the kinematic and kinetic data and determine the three-dimensional position of each marker as described by Petersen $e t$ al. $^{33}$ The data from the motion files will be low-pass filtered with a fourth order Butterworth filter with a cut-off frequency of $8 \mathrm{~Hz}$. A standard three-dimensional inverse dynamics method based on Newton-Euler equations will be used to quantify the relevant forces and moments acting on the lower limb joints. Moment data for each participant will be normalised by dividing by body mass to enable comparison with results obtained in similar studies in the literature. For each participant and for each movement, ankle, knee, hip, pelvis and trunk kinematics will be calculated. Kinetics will be calculated during walking, stair descending and jumping. The average of at least three measurements will be computed for all movements. Gait quality will be described with the Gait Deviation Index. ${ }^{18}$

\section{Muscle strength and electromyography assessment}

All data will be sampled using TeleMyo Direct Transmission System and MyoResearch Software (Noraxon, Scottsdale, Arizona, USA) at $1500 \mathrm{~Hz}$, and analyses will be performed using custom-made software. Torque data will be filtered using a Butterworth low-pass filter (cut-off frequency: $6 \mathrm{~Hz}$ ), and the gravity adjusted. Contraction onset will be defined as when the torque increases above $7.5 \mathrm{Nm}$ and MVC will be defined as the peak torque measurement. Maximal RFD will be defined as the steepest slope between onset and MVC. Additionally, RFD will be determined as the average slope from 0 to $50 \mathrm{~ms}$ and 0 to $200 \mathrm{~ms}$ after onset of contraction. ${ }^{37}$ All torque measurements will be normalised to body mass.

\section{Daily activities}

Accelerometer outcomes will be analysed with a custom developed MATLAB algorithm. ${ }^{38}$ Outcomes are: percentage rest, standing, walking, cycling, swimming and high-impact activity, number of steps, number of sit to stands and total time wearing the accelerometer. Outcomes will be means of 5 days of measurement. If a participant has recorded activity for less than $10 \mathrm{~h}$ a day, that day will be excluded. ${ }^{24}$ In case of data errors or missing data, a minimum of 3 days of $10 \mathrm{~h}$ is needed; otherwise, the data will be excluded.

\section{Sample size calculation}

Although this cohort study has several central outcome measures, the primary outcome variable which the main sample size is based on is isometric hip flexor peak torque. The sample size is based on preoperative (mean 1.25, standard deviation (SD) 0.55 ) and postoperative (mean 1.50) hip flexor peak torque values from Casartelli et al $;^{23}$ applying a level of significance of 0.05 and a power of $90 \%$, the patient group should consist of at least 53 persons. To allow for possible dropouts, our goal is to include 60 patients. Owing to the inconsistency of results from biomechanical studies in the FAI-patient group, biomechanical measures from patients with hip dysplasia are used to check if this part of the study is powered sufficiently. Preoperative values of peak hip flexion moments (mean 0.57, SD .22) and 1 year postoperative (mean 0.80), ${ }^{39}$ with a level of significance of 0.05 , a power of $90 \%$ suggests that approximately 12 patients are sufficient for this test, making our design solid for this part of the study as well. For the physical activity measurements, a convenient sample of 60 will be used. For the HAGOS scores, a sample of 15-48 patients is required, depending on the subscale. ${ }^{40}$ Sample sizes for central outcomes are listed in table 2. Our goal is to include 60 patients with a full 1-year follow-up within 3 years. The reference group will consist of 30 agematched and gender-matched persons, which will be sufficient for statistical tests compared to the patient group (based on reference data for hip flexor peak torque ${ }^{23}$ and hip flexion moment during walking ${ }^{39}$ ).

\section{Statistical considerations}

Patients and the reference group will be compared with multiple regression analysis adjusted for age and gender if the assumptions for this model are met. Otherwise, corresponding non-parametric statistics will be applied. The preoperative-to-postoperative evaluations will be analysed with paired parametric statistics. Where measurements are repeated more than once, a mixed-effects model will be applied if the assumptions for the analysis are met. If not, corresponding non-parametric statistics will be applied. Subgroup analyses will be included in the mixed-effects model where appropriate. If distribution of data indicates that subgrouping by age and gender is relevant, these groups will be compared with non-paired statistics. The level of significance will be 0.05 . Effect sizes will be calculated where appropriate.

\section{Ethics and dissemination}

All participants will give their written informed consent prior to participation in accordance with the

Table 2 Sample sizes for central outcome measures

\begin{tabular}{ll}
\hline Outcome measure & $\mathbf{n}$ \\
\hline Hip flexor peak torque & 53 \\
Hip flexion moment during walking & 12 \\
Physical activity & 60 \\
Copenhagen Hip and Groin Outcome Score & 48 \\
\hline
\end{tabular}


Declaration of Helsinki II. The cohort is registered at clinicaltrials.gov (NCT02306525).

The results from this study will be presented at congresses and published in peer-reviewed journals.

\section{DISCUSSION}

Arthroscopic hip surgery has been offered as a treatment for FAI during the past decade and our experience with the procedure is still growing. This cohort will provide information about the natural time course of self-reported and objectively measured outcomes prior to and following hip arthroscopy for FAI. Our results will enable analysis of the outcome of the surgery and here highlight possible target areas for further intervention and rehabilitation. Furthermore, if it is possible to subgroup patients into cam/pincer/mixed, valuable information about the differences between these subgroups will be obtained from this study. A limitation is that owing to the large number of functional tests applied in this study, it is not possible to include a sufficiently large number of patients to secure subgroup analyses. Hence, it is not certain that enough patients will be available for subgroup analyses. On the other hand, this study provides a detailed analysis of performance measures not seen in similar large scale. Possible subgroup patterns identified in this cohort may be investigated in future studies powered for this purpose.

The inclusion of an age-matched and gender-matched reference group is a strength of this study since it is here possible to analyse if patients reach reference values 1 year after surgery. It is not taken into account if the reference group has asymptomatic cam and/or pincer deformities based on hip radiographs. Our reference group is therefore clinically, but not necessarily radiographically, healthy. This should be taken into consideration when interpreting the results.

The efficacy of arthroscopic hip surgery is not documented in a placebo-controlled randomised trial. Nevertheless, arthroscopic hip surgery seems to improve patient-reported outcomes, and therefore the primary goal for this study is to evaluate the present treatment strategy offered to patients with FAI. The results of this cohort study may highlight possible target areas for prehabilitation and rehabilitation areas and create a base for future possible randomised studies. We intend to perform future studies with long-term follow-up of this cohort, describing the rate of reoperations, conversions to total hip arthroplasty and development of OA.

Contributors All authors helped design the study. SK wrote the initial draft for the protocol manuscript, IM and UD helped revise it and all authors approved the final version of the manuscript.

Funding This work was supported by the Danish Rheumatism Association, the Aase \& Ejnar Danielsen Foundation, the Augustinus Foundation, the AP Møller Foundation, the Hede Nielsen Foundation, the Gurli \& Hans Engell Friis Foundation, the Madsen Foundation and the Horsens Hospital, Denmark.
Competing interests None declared.

Ethics approval The Central Denmark Region Committee on Biomedical Research Ethics approved the study (1-10-72-239-14) and the Danish Data Protection Agency gave permission for the handling of personal data (1-16-02-499-14).

Provenance and peer review Not commissioned; externally peer reviewed.

Open Access This is an Open Access article distributed in accordance with the Creative Commons Attribution Non Commercial (CC BY-NC 4.0) license, which permits others to distribute, remix, adapt, build upon this work noncommercially, and license their derivative works on different terms, provided the original work is properly cited and the use is non-commercial. See: http:// creativecommons.org/licenses/by-nc/4.0/

\section{REFERENCES}

1. Agricola R, Waarsing $\mathrm{JH}$, Arden NK, et al. Cam impingement of the hip-a risk factor for hip osteoarthritis. Nat Rev Rheumatol 2013;9:630-4.

2. Beck M, Kalhor M, Leunig M, et al. Hip morphology influences the pattern of damage to the acetabular cartilage: femoroacetabular impingement as a cause of early osteoarthritis of the hip. $J$ Bone Joint Surg Br 2005;87:1012-18.

3. Crawford JR, Villar RN. Current concepts in the management of femoroacetabular impingement. J Bone Joint Surg $\mathrm{Br}$ 2005;87:1459-62

4. Frank JM, Harris JD, Erickson BJ, et al. Prevalence of femoroacetabular impingement imaging findings in asymptomatic volunteers: a systematic review. Arthroscopy 2015;31:1199-204.

5. Agricola R, Bessems JH, Ginai AZ, et al. The development of Cam-type deformity in adolescent and young male soccer players. Am J Sports Med 2012;40:1099-106.

6. Ganz R, Parvizi J, Beck M, et al. Femoroacetabular impingement: a cause for osteoarthritis of the hip. Clin Orthop Relat Res 2003;417:112-20

7. Walker JA, Pagnotto M, Trousdale RT, et al. Preliminary pain and function after labral reconstruction during femoroacetabular impingement surgery. Clin Orthop Relat Res 2012;470:3414-20.

8. Palmer DH, Ganesh V, Comfort T, et al. Midterm outcomes in patients with cam femoroacetabular impingement treated arthroscopically. Arthroscopy 2012;28:1671-81.

9. Naal FD, Miozzari HH, Schar M, et al. Midterm results of surgical hip dislocation for the treatment of femoroacetabular impingement. $A m ~ J$ Sports Med 2012;40:1501-10.

10. Nho SJ, Magennis EM, Singh CK, et al. Outcomes after the arthroscopic treatment of femoroacetabular impingement in a mixed group of high-level athletes. Am J Sports Med 2011;39 (Suppl):14S-19S.

11. Ribas M, Ledesma R, Cardenas C, et al. Clinical results after anterior mini-open approach for femoroacetabular impingement in early degenerative stage. Hip Int 2010;20(Suppl 7):S36-42.

12. Wall PD, Brown JS, Parsons N, et al. Surgery for treating hip impingement (femoroacetabular impingement). Cochrane Database Syst Rev 2014;(9):CD010796.

13. Diamond LE, Dobson FL, Bennell KL, et al. Physical impairments and activity limitations in people with femoroacetabular impingement: a systematic review. Br J Sports Med 2015;49:230-42.

14. Bozic KJ, Chan V, Valone FH III, et al. Trends in hip arthroscopy utilization in the United States. J Arthroplasty 2013;28(8 Suppl): 140-3.

15. Casartelli NC, Maffiuletti NA, Item-Glatthorn JF, et al. Hip muscle weakness in patients with symptomatic femoroacetabular impingement. Osteoarthritis Cartilage 2011;19:816-21.

16. Rylander J, Shu B, Favre J, et al. Functional testing provides unique insights into the pathomechanics of femoroacetabular impingement and an objective basis for evaluating treatment outcome. J Orthop Res 2013;31:1461-8.

17. Lamontagne M, Brisson N, Kennedy MJ, et al. Preoperative and postoperative lower-extremity joint and pelvic kinematics during maximal squatting of patients with cam femoro-acetabular impingement. J Bone Joint Surg Am 2011;93(Suppl 2):40-5.

18. Schwartz MH, Rozumalski A. The Gait Deviation Index: a new comprehensive index of gait pathology. Gait Posture 2008;28:351-7.

19. Rylander JH, Shu B, Andriacchi TP, et al. Preoperative and postoperative sagittal plane hip kinematics in patients with 
femoroacetabular impingement during level walking. Am J Sports Med 2011;39(Suppl):36S-42S.

20. Kennedy MJ, Lamontagne M, Beaule PE. Femoroacetabular impingement alters hip and pelvic biomechanics during gait Walking biomechanics of FAl. Gait Posture 2009;30:41-4.

21. Hunt MA, Guenther JR, Gilbart MK. Kinematic and kinetic differences during walking in patients with and without symptomatic femoroacetabular impingement. Clin Biomech (Bristol, Avon) 2013;28:519-23.

22. Alradwan $\mathrm{H}$, Khan M, Hamel-Smith Grassby M, et al. Gait and lowe extremity kinematic analysis as an outcome measure after femoroacetabular impingement surgery. Arthroscopy 2015;31:339-44.

23. Casartelli NC, Maffiuletti NA, Item-Glatthorn JF, et al. Hip muscle strength recovery after hip arthroscopy in a series of patients with symptomatic femoroacetabular impingement. Hip Int 2014:24:387-93.

24. Harris-Hayes M, Steger-May K, Pashos G, et al. Stride activity level in young and middle-aged adults with hip disorders. Physiother Theory Pract 2012;28:333-43.

25. Kroman SL, Roos EM, Bennell KL, et al. Measurement properties of performance-based outcome measures to assess physical function in young and middle-aged people known to be at high risk of hip and/or knee osteoarthritis: a systematic review. Osteoarthritis Cartilage 2014;22:26-39.

26. Kivlan BR, Martin RL. Functional performance testing of the hip in athletes: a systematic review for reliability and validity. Int J Sports Phys Ther 2012;7:402-12.

27. Thorborg K, Holmich P, Christensen R, et al. The Copenhagen Hip and Groin Outcome Score (HAGOS): development and validation according to the COSMIN checklist. Br J Sports Med 2011;45:478-91.

28. Tönnis D. Congenital dysplasia and dislocation of the hip in children and adults. Berlin, Germany: Springer, 1987.

29. Hawker GA, Mian S, Kendzerska T, et al. Measures of adult pain: Visual Analog Scale for Pain (VAS Pain), Numeric Rating Scale for Pain (NRS Pain), McGill Pain Questionnaire (MPQ), Short-Form McGill Pain Questionnaire (SF-MPQ), Chronic Pain Grade Scale (CPGS), Short Form-36 Bodily Pain Scale (SF-36 BPS), and Measure of Intermittent and Constant Osteoarthritis Pain (ICOAP). Arthritis Care Res (Hoboken) 2011;63(Suppl 11):S240-52.
30. Preedy V, Watson R. Handbook of disease burdens and quality of life measures. New York, USA: Springer, 2010.

31. Mannion AF, Impellizzeri FM, Naal FD, et al. Fulfilment of patient-rated expectations predicts the outcome of surgery for femoroacetabular impingement. Osteoarthritis Cartilage 2013;21:44-50

32. Paulsen A, Roos EM, Pedersen AB, et al. Minimal clinically important improvement (MCII) and patient-acceptable symptom state (PASS) in total hip arthroplasty (THA) patients 1year postoperatively. Acta Orthop 2014;85:39-48.

33. Petersen J, Nielsen RO, Rasmussen S, et al. Comparisons of increases in knee and ankle joint moments following an increase in running speed from 8 to 12 to $16 \mathrm{~km} . \mathrm{h}$. Clin Biomech (Bristol, Avon) 2014;29:959-64.

34. Monaghan K, Delahunt E, Caulfield B. Increasing the number of gait trial recordings maximises intra-rater reliability of the CODA motion analysis system. Gait Posture 2007;25:303-15.

35. Gandevia SC. Spinal and supraspinal factors in human muscle fatigue. Physiol Rev 2001;81:1725-89.

36. Ratzlaff $\mathrm{C}$, Simatovic $\mathrm{J}$, Wong $\mathrm{H}$, et al. Reliability of hip examination tests for femoroacetabular impingement. Arthritis Care Res (Hoboken) 2013;65:1690-6.

37. Kjolhede T, Vissing K, de Place L, et al. Neuromuscular adaptations to long-term progressive resistance training translates to improved functional capacity for people with multiple sclerosis and is maintained at follow-up. Mult Scler 2015;21:599-611.

38. van Rooij WM, Senden R, Heyligers IC, et al. Physical functioning of low back pain patients: perceived physical functioning and functional capacity, but not physical activity is affected. Disabil Rehabil 2015 [epub ahead of print $26 \mathrm{Jul} 2015$ ]

39. Jacobsen JS, Nielsen DB, Sorensen $\mathrm{H}$, et al. Joint kinematics and kinetics during walking and running in 32 patients with hip dysplasia 1year after periacetabular osteotomy. Acta Orthop 2014;85:1-8.

40. Thomee R, Jonasson $\mathrm{P}$, Thorborg $\mathrm{K}$, et al. Cross-cultural adaptation to Swedish and validation of the Copenhagen Hip and Groin Outcome Score (HAGOS) for pain, symptoms and physical function in patients with hip and groin disability due to femoro-acetabular impingement. Knee Surg Sports Traumatol Arthrosc 2014:22:835-42. 